\title{
Blockchain as an enabling technology in the COVID-19 pandemic: a systematic review
}

\author{
Pedro Henrique Ribeiro Botene ${ }^{1}\left(\mathbb{D} \cdot\right.$. Anibal Tavares de Azevedo ${ }^{2}$ (D) Paulo Sérgio de Arruda Ignácio ${ }^{1}$ (i)
}

Received: 8 June 2021 / Accepted: 30 August 2021 / Published online: 6 September 2021

(c) IUPESM and Springer-Verlag GmbH Germany, part of Springer Nature 2021

\begin{abstract}
The impacts caused by the unprecedented transmission of COVID-19 have given rise to new challenges that are shaking the structures of humanity. Several enabling technologies are currently being used as key strategies in creating improvements and responses to the difficulties created by the pandemic and blockchain is one of these solution proposals. Within this scenario, this work aims to study and analyze how the blockchain technology can help in the struggle against the COVID-19 pandemic through a systematic review of the literature. Although the study is limited by the moment when the crisis is still in progress, the results show that it is clear that the adoption of the blockchain can effectively help in the fight against the coronavirus, considering that the main features of the blockchain can support the successful implementation of many use cases. This paper has the role of assisting academics and professionals in identifying the application focus of the blockchain, as well as showing the main opportunities and challenges and the relevance of the subject to the current context of the pandemic.
\end{abstract}

Keywords Blockchain · Distributed Ledger · COVID-19 · Systematic Review

\section{Introduction}

The COVID-19 pandemic has affected almost all countries and has had a significant effect on the human lives and economical activities. Manufacturing operations, supply chain and logistics are facing serious disruptions [1], healthcare teams are dealing with a high burden of work [2] and people are going through changes in their lifestyle.

Technological advances as artificial intelligence (AI) and machine learning (ML), internet of things (IoT), blockchain, robotics, 5G, nanotechnology, synthetic biology, cloud and edge computing and big data are one of the key strengths of the current era that may help the world to overcome the challenges posed by COVID-19, creating intelligent emergency

This article is part of the COVID-19 Health Technology: Design, Regulation, Management, Assessment

Pedro Henrique Ribeiro Botene

phbotene@gmail.com

1 School of Applied Sciences, University of Campinas, (Industrial Engineering Research Center), Limeira, São Paulo, Brazil

2 School of Applied Sciences, University of Campinas, (Operations Research Center), Limeira, São Paulo, Brazil strategies and improving public health response to the pandemic [3].

Some authors even discuss the use of these technologies in an integrated way to fight COVID-19, such as the collaboration of blockchain and multi-robot and multi-drones in order to optimize a End-to-End chain, monitoring and detecting important aspects of the pandemic, including social distance and body temperature, and delivering medical supplies [4, 5].

According to Tan et al. [6] blockchain technology is one of the many disruptive technologies of the Fourth Industrial Revolution that will inevitably change the way people live and work. In a research made by Kritikos [7], the blockchain was considered one of the 10 most recommended technologies to combat COVID-19.

Blockchain is an electronic cryptographic ledger that operates on a decentralized network model, instead of storing all information in a single database as in traditional cloud-based applications, the information is distributed and synchronized across all nodes in the network [8]. The blocks (set of transactions) in the network of the blocking chain are checked by the most of the nodes. Hash values can be incorporated into a storage chain format to verify that stored data is tampered with to ensure data integrity. The digital signature is used to verify the actual identities 
of the providers and receivers of data in the stored transactions. Additionally, the consensus mechanism is designed to involve all computer nodes, thus reducing the potential risks of data manipulation by minority attackers. After validation, the block is added to the chain shared by all nodes in a network [9-11].

As [12] shows, blockchain is broadly classified into three types: public, private and consortium. Public blockchain is the one that anyone can effectively participate in the network, private blockchain is a restricted network which only authorized participants can take part in [13] and in the consortium blockchain, the right to read Blockchain can be public or restricted to participants only. Moreover, the consortium blockchains are considered partially decentralized in contrast to the private Blockchains [12].

Blockchain is gaining increasingly prominence due to its wide applications in various sectors of life. Seeing its utility, several companies and authorities around the world have started to use blockchain to develop solutions that can help to fight COVID-19 [14]. Clinical trial management, medical supply chain, user privacy protection, data aggregation, contact tracing, donation tracking and outbreak tracking are some mainly use cases of blockchain for COVID-19 [15].

Within this scenario, the objective of this study was to make a systematic analysis of the implementation and/or use of the blockchain technology applied in the struggle against the pandemic, in diverse segments. The proposal was to answer the following question through the systematic review of the literature:

\subsection{How blockchain technology can help a pandemic situation like COVID-19?}

The main contributions of this paper are as follows:

Determining the number of studies published since the start of the pandemic;

Identifying the countries that have produced more and published the most solutions to combat COVID-19;

$\bigcirc$ Representing an overview of research areas related to using blockchain against COVID;

Identifying the main approaches adopted by the published studies;

$\bigcirc$ Determining the types of blockchain and platforms most commonly used for this purpose;

$\bigcirc$ Investigating the published studies in terms of their area of application;

$\bigcirc$ Identifying and discussing the main challenges and opportunities of using blockchain to combat COVID-19.

Section 2 of this paper presents the methodology and the data treatment approach. Section 3 illustrates the results of the systematic review. Section 4 shows the findings and discussion, and Sect. 5 concludes the study.

\section{Methodology}

This is an exploratory study, which aims to provide a more approximate overview, about a certain issue, developing, clarifying concepts and refining ideas [16]. It has a qualitative approach, that has a systematic and comprehensive process, needs data selection, simplification, presentation and conclusion/verification, in which data treatment includes an analysis activity, the data is segmented into relevant units [17].

Systematic review provides an evidence-based approach to identify, select, and analyze data, differing from other review methods due to its principles, which allow a more objective view of the results, eliminating any issues of bias and error [18].

This research method aims to analyze the studies on the main subject matter of this research. This method also allows to analyze the studies already published on this thematic and creates a solid base for advanced knowledge, facilitates the development of theories, concludes the areas where there have been many studies and discovers new areas of research, being essential for any type of academic project $[19,20]$.

To provide a transparent, reproducible and scientific literature review of blockchain-based applications in COVID19 situations, this review followed the Preferred Reporting Items for Systematic reviews and Meta-Analyses (PRISMA) guidelines [21]. PRISMA is a set of evidence-based elements that helps authors improve the reporting of systematic reviews and meta-analyses, which can be used as the basis for reporting systematic reviews [21, 22].

\subsection{Study protocol}

The study protocol phase is about determining the eligibility criteria (inclusion and exclusion), the sources of information, and the search strategy (main question, objectives, keywords, language, and type of document), shown in Table 1.

The searches for these data were conducted in July 2021. The databases chosen were Scopus and Web of Science because they are important and recognized for their relevance to articles in the field of engineering III.

\subsection{Study selection}

The first result showed a range of 724 documents found (697 in "Scopus" and 27 in "Web of Science"). Thereafter, some filters were selected as "only articles", "English language" and "open access", and no filter was used for period, since the theme is relatively new. After those filters and duplicated 
Table 1 Full research protocol

\begin{tabular}{ll}
\hline Protocol & Parameter \\
\hline $\begin{array}{l}\text { Main question } \\
\text { Objectives }\end{array}$ & $\begin{array}{l}\text { How blockchain technology can help a pandemic situation like COVID-19? } \\
\text { Systematic analysis of the implementation and/or use of blockchain in facing } \\
\text { the pandemic, in the most diverse segments } \\
\text { Scopus and Web of Science }\end{array}$ \\
$\begin{array}{l}\text { Source engine } \\
\text { Bearch keywords }\end{array}$ & $\begin{array}{l}\text { Papers and conference papers } \\
\text { Document type }\end{array}$ \\
English \\
Inclusion criteria & IC1: Papers using blockchain as a solution to COVID-19 \\
& IC2: Papers published and fully available in the scientific bases \\
Exclusion criteria & EC1: Papers COVID-19 but are not related to blockchain \\
& EC2: Papers that refer to blockchain but are not related to COVID-19 \\
& EC3: Papers that discuss neither COVID-19 nor blockchain \\
& EC4: Papers not available for complete reading \\
\hline
\end{tabular}

removal, a total of 471 documents were discarded, and the final number of articles selected was 253 .

With the filtered list of articles, the results were exported to an auxiliary tool. In this case the software R Studio with bibliometrix [23] was chosen due to its versatility. The data exported from both databases were converted into a single file. Then it was uploaded to a Microsoft Excel spreadsheet where it was possible to classify the papers according to the relevance of the subject in relation to the work being performed. In addition, it allows the user to include the details and their comments on the paper. The systematic flow followed to the paper selection process can be seen in Fig. 1.

In the eligibility step, the 253 selected papers from stage 1 were filtered regarding title, keywords and abstract. Those that met the inclusion criteria in this stage were considered approved. The 39 approved papers were submitted to the classification phase.
Fig. 1 Selection of articles in the Scopus and Web of Science databases
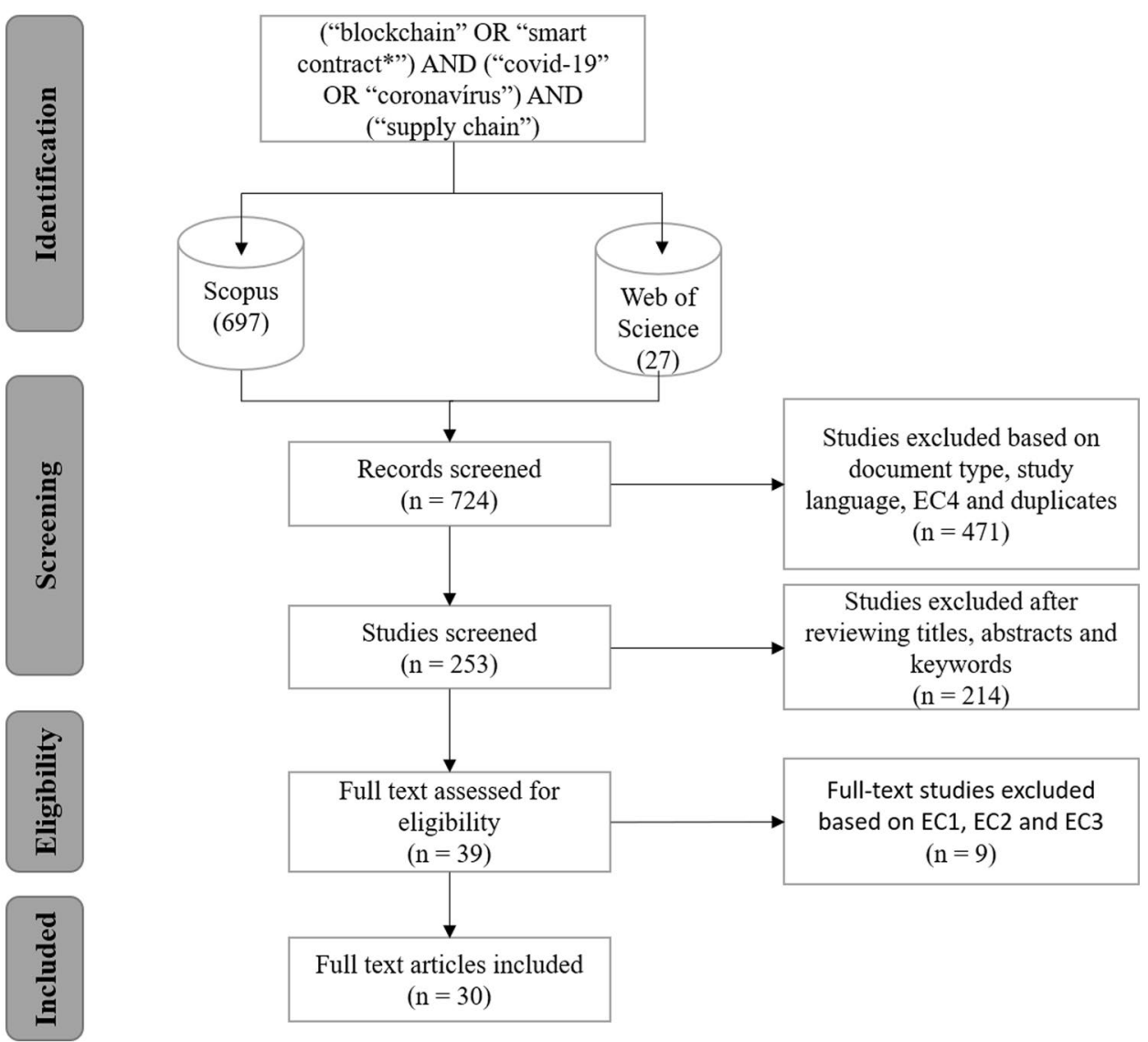


\subsection{Data collection and classification}

At this stage the 39 articles that were approved in the previous filters were read in full. Simultaneously to the reading, a specific data collection of each one was made using the Excel 2019 tool. After the full reading, 30 papers were selected for the final analysis.

The papers were classified according to parameters: general bibliometrics (country, month and subject area) and systematic (research method, and application area, blockchain characterization). The discussion was classified as "improvements and difficulties" and the conclusion were the final topic.

\section{Results}

\subsection{Bibliometric review}

This section presents the main results of the bibliometric analysis of the 30 approved papers, concerning the number of published references grouped by the main areas of research concentration, by month and by country.

The research fields observed in Fig. 2 show the areas of research concentration of the selected articles. Computer
Science appears in the first, justified by the fact that blockchain involves knowledge related to computing, programming and other technologies, such as artificial intelligence. Engineering is the second one, indicating that blockchain is a subject very connected to the application of scientific, mathematical, statistical and creative knowledge to create and implement technology environments. Also in the second place, there is Social Science, as the pandemic had a dramatic social impact all over the world. In third place comes Medicine indicating that, although blockchain is a subject very connected to technical area, it has extreme relevance in the health field due to the fact that it is being used to combat COVID-19, and this disease has a profound impact on the individuals' lives.

Figure 3 shows the country scientific production. The countries with the most publications are China (18\%), India (16\%), Australia (14\%), Italy (10\%), and the UK (10\%). Together, these countries account for approximately $70 \%$ of all scientific production on blockchain and COVID-19.

It is interesting to link some facts to these countries. For example, India, Italy and the UK were severely affected by the pandemic at certain peak times, where India became the second largest country with number of cases [24, 25].

China, the place where the pandemic started, as well as Australia, managed a good fight against the virus, as they

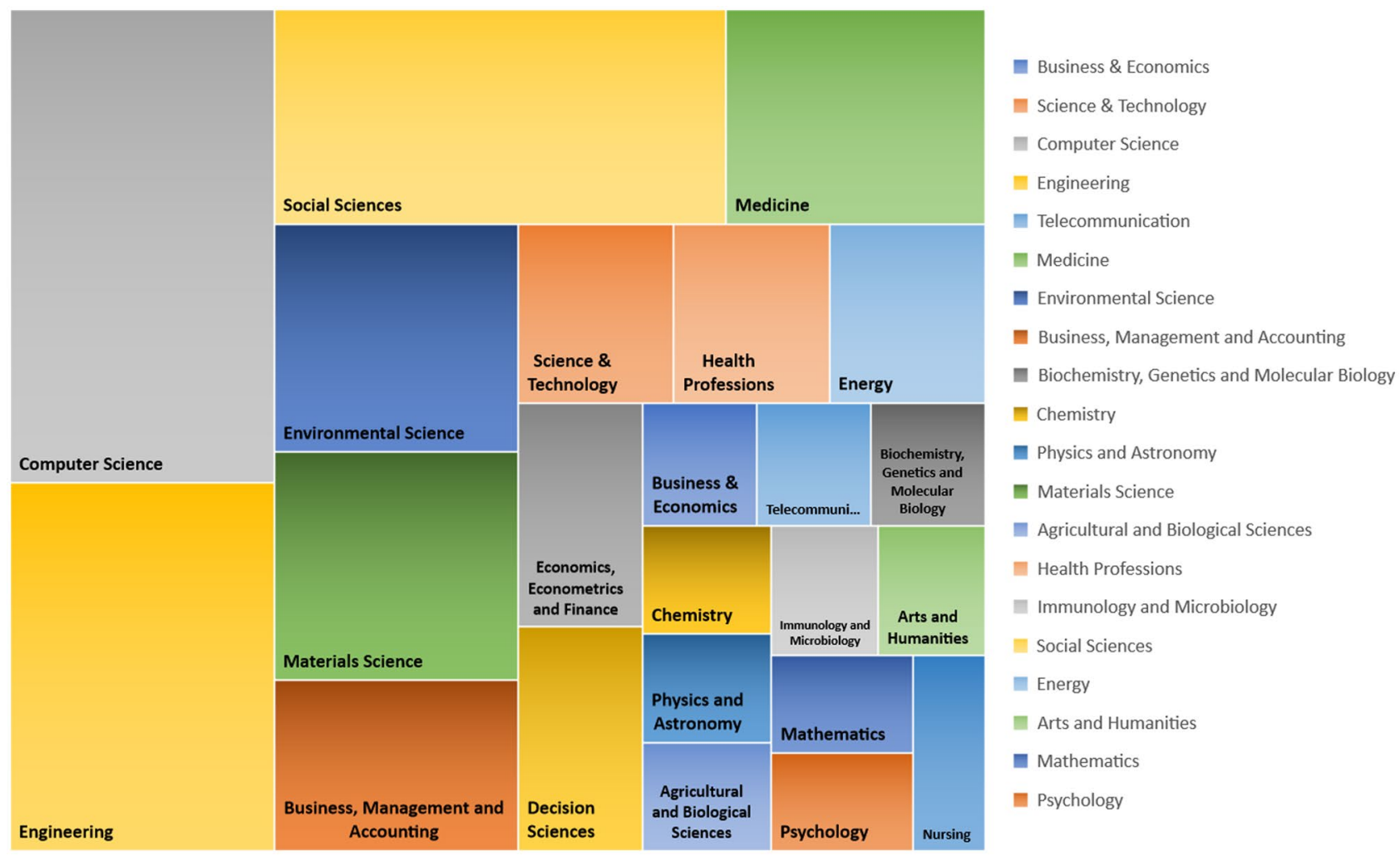

Fig. 2 Research concentration areas 
Fig. 3 Country scientific production

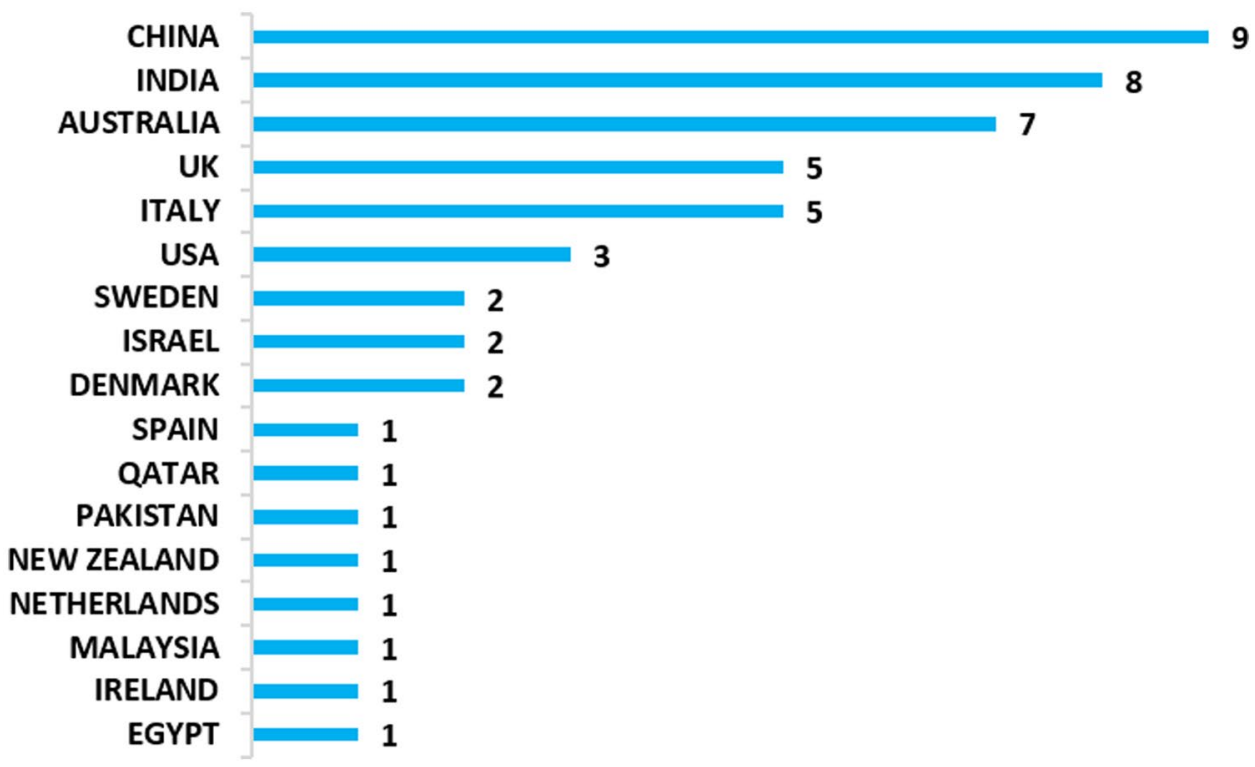

worked tirelessly together to bring the disease to this very low level [26, 27].

The other countries with scientific publications are: United States, Denmark, Israel, Sweden, Egypt, Ireland, Malaysia, the Netherlands, New Zealand, Pakistan, Qatar and Spain.

Another interesting fact is that the top countries (China, India, Australia, Italy, UK) and some countries with smaller entries (US, Denmark, Sweden and Netherlands) are included in the list of vaccine producing countries with functional NRAs (The National Regulatory Authorities) [28].

Although this is a fairly motivator, it is not possible to state that there is a relationship between how affected a country was with its scientific production about the topic. However, it is possible to assume that there is a tendency for some countries to lead, while others implement similar measures later [29]. The data presented in this section illustrate the capacity and pro-activity of countries to mobilize their intellectual capital, regardless of how it has been affected.

Figure 4 shows the corresponding author's country. MCP means Multiple Countries Publication, indicating for each country, the number of papers in which there is at least one co-author from a different country, i.e., it measures the intensity of a country's international collaboration. SCP stands for Single Countries Publication, in which there is only one corresponding author.

As can be seen, UK and Australia are the only countries with international collaboration.

Because COVID-19 is a recent subject, Fig. 5 presents an updated scenario of the number of papers published per month. It can be observed that the first articles were published at the beginning of 2020, more specifically in April, period in which the pandemic started to gain more notoriety outside of China. The increase of publications happened in May, month in which the pandemic started to assume a global proportion, affecting almost all countries of the globe, as it has also been showed by [24].

March 2021 is the month with the highest number of publications. One possible reason for this outcome is that research which was carried out in 2020 (the peak year of the pandemic), while the world was experiencing the challenges posed by COVID-19, was completed earlier this year, and was published during this month in the first quarter of the year.

Although there are variations in the numbers of publications over the months shown, the trend line shows a direction of growth in publications, albeit small, for the coming months. As the COVID-19 pandemic has led researchers from various fields of knowledge to work intensively, the use and applicability of blockchain is gaining even more notoriety by enterprises and the academic field, and the development of new solutions becomes easier and more and more accepted by the population, with more precise applications.

\subsection{Studies classification}

The studies were classified by the research method (see Fig. 6). The categories are defined based on [30], being:

Theoretical-conceptual (TC) - studies are based on theory, such as literature reviews, systematic reviews or conceptual discussions; 


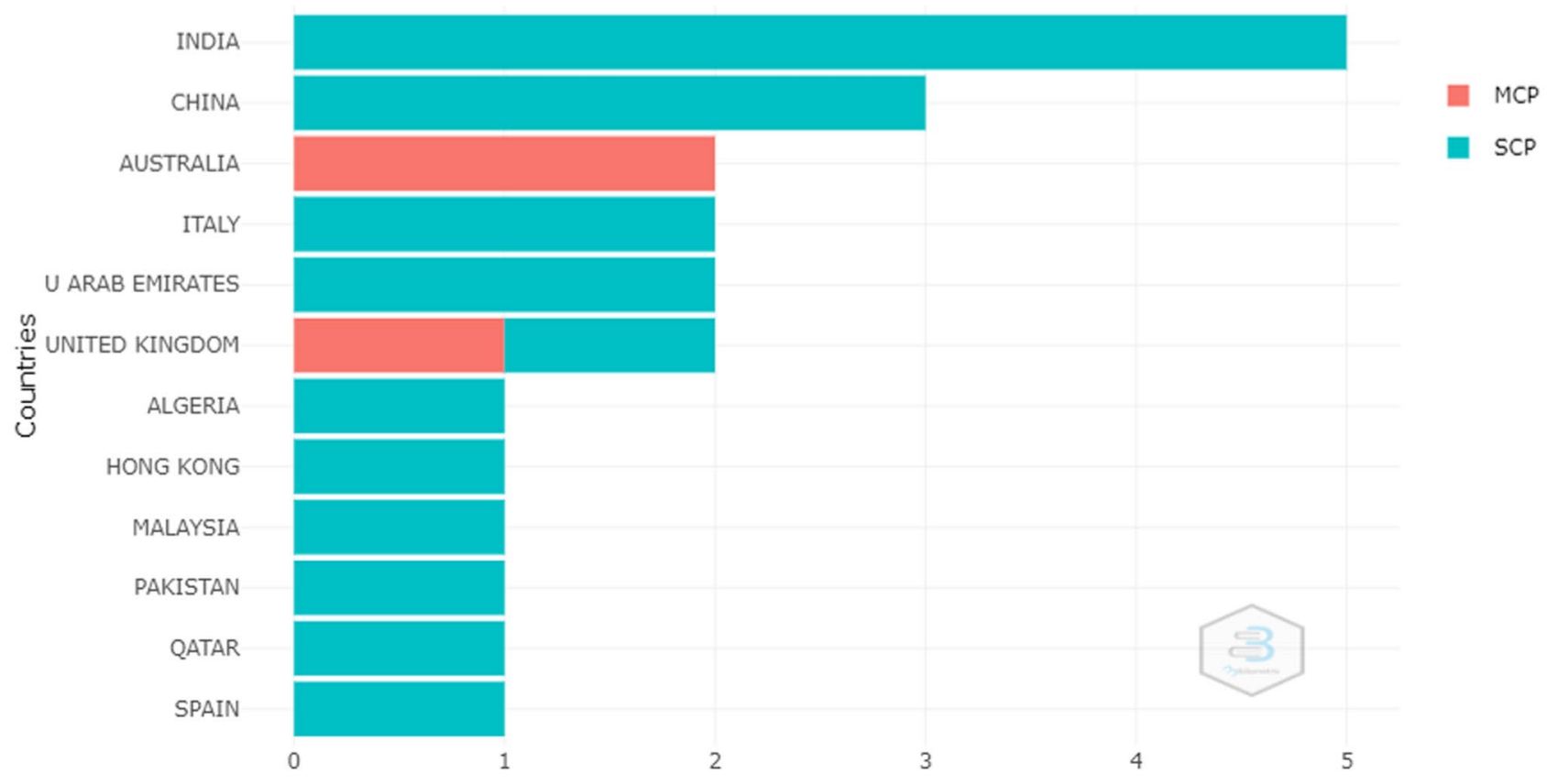

N. of Documents

Fig. 4 Corresponding author's country (bibliometrix)

$\bigcirc$ Action Research (AR) - a type of empirical study that approaches an action or resolution of a collective problem and involves the researcher and participants of the situation;

$\bigcirc$ Case study (CS) — an approach of multiple methods and tools from data collection that has no direct impact on the problem, but rather is a type of simulation;

O Survey (S) - quantitative procedure for information collection through questionnaires or interviews.
The result shows that, from 30 papers, 17 were identified as TC, such as the studies from [14, 31, 32] which present a discussion of the use of blockchain in the fight against COVID through some cases, as facilitating increased testing and reporting, recording the details of the COVID-19 patients, managing the lockdown implementation, limiting supply chain disruptions, for a trace-route for a COVID-19 safe clinical practice or even propose a supply chain integration framework to overcome the pandemics shortfall.
Fig. 5 Publications by month - Scopus and Web of Science databases

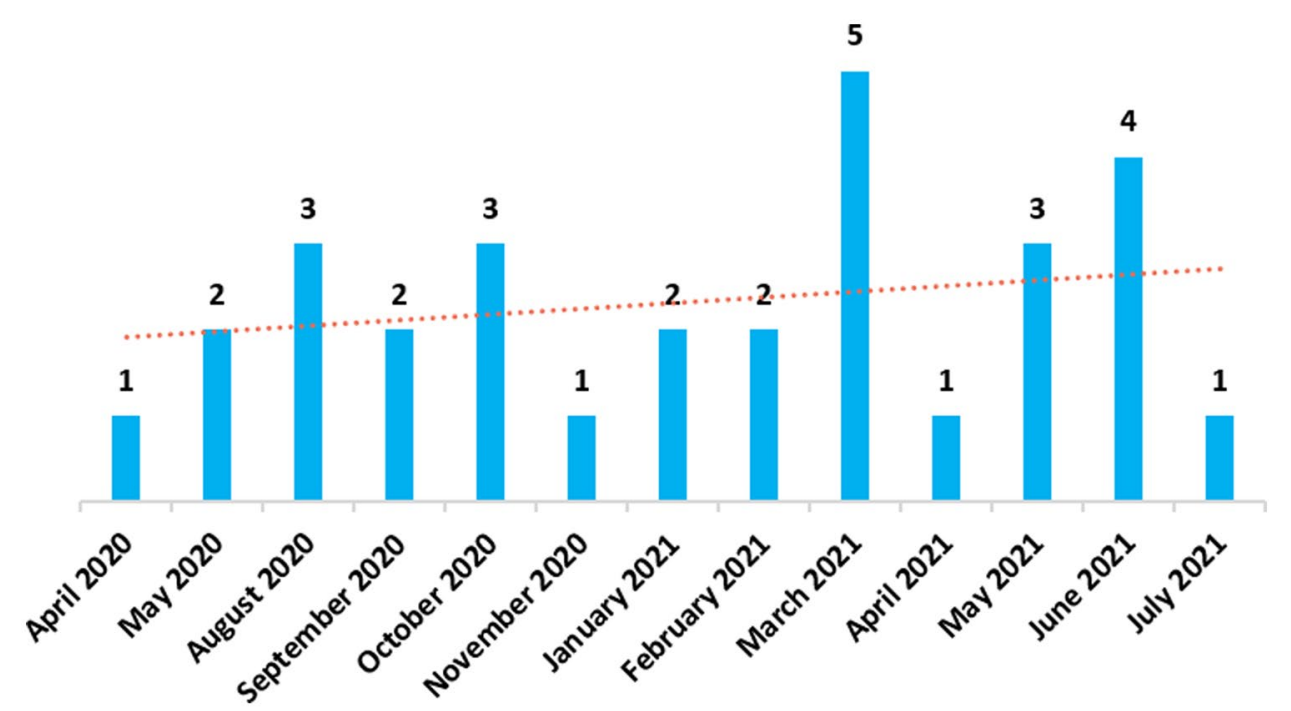




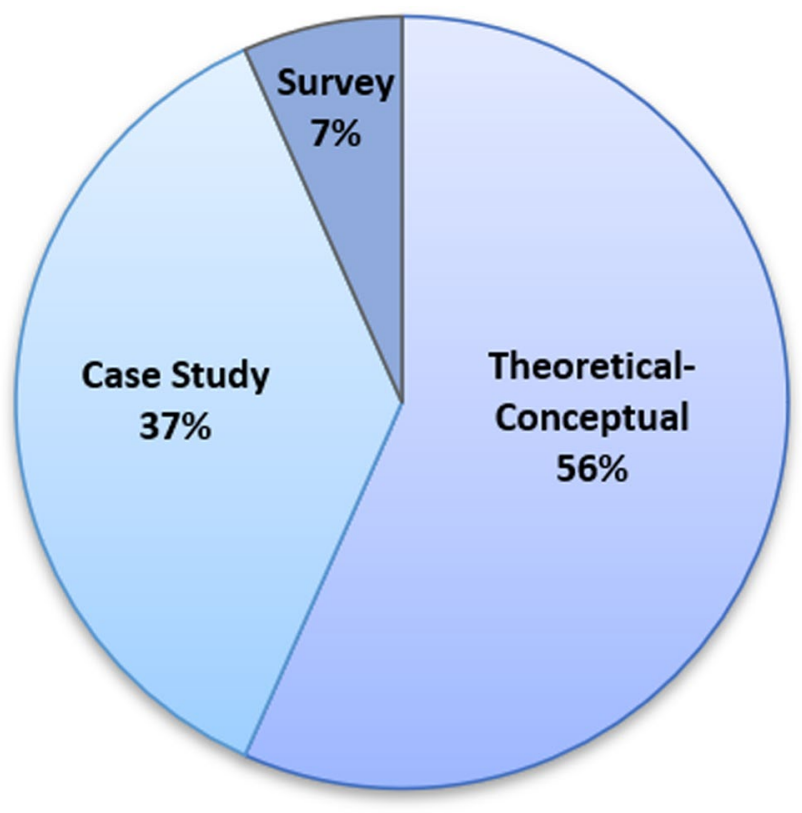

Fig. 6 Classification by research method

The others 11 papers were represented by Case Study, as the studies from [1] that examined the viability of using blockchain technology in a public distribution system (PDS) supply chain to overcome issues of shrinkage, misplacement and ghost demand, [15] who proposed, implemented, and evaluated a blockchain-based system using Ethereum smart contracts and oracles to track reported data related to the number of new cases, deaths, and recovered cases obtained from trusted sources, and [33] who created an intelligent framework that is designed to deal with the severe shortage of PPE for the medical team, reduce the massive pressure on hospitals, and track recovered patients to treat COVID-19 patients with plasma.

Lastly, there are 2 papers classified as a survey. These papers are from [34], which consists in identify the factor that can be improved and reliable using blockchain-based technology in requirement engineering for COVID-19 software projects, and from [35] that aimed to provide insights into how to gain consumer loyalty through the use of blockchain.

Table 2 shows the classification of each study.

\subsection{Main application areas}

With the pandemic, many studies have emerged on how various sectors will cope with the current crisis, and considering the global context of connectivity and information, blockchain technology has a significant impact in this scenario.

Figure 7 shows the areas that were mentioned in the studies analyzed for this review. As it is a pandemic that is causing a global health crisis, the first two most mentioned areas were: Public Health $(31 \%)$ and Healthcare (26\%). Together, these two areas that symbolize the broad area of health represent about $60 \%$ of all mentioned. These papers propose assistance to authorities in assuring that the COVID-19 medical waste is disposed of properly and COVID-19 testing centers are using genuine medical equipment to treat COVID-19 patients [36], a solution for managing data related to COVID-19 vaccines' distribution and delivery [37], to develop a tracking system for COVID-19 data collected from external sources and ensure privacy, trust and traceability for patients' information [3, 31, 38, 39].

Other areas have also received studies related to the current pandemic and the blockchain technology. For instance, in the logistics area, [1] proposed a model to evaluate the viability of using blockchain in a public distribution supply chain system to overcome issues as inaccuracies and demand disruptions, and [40] aimed to develop a crossborder capacity-building framework for small and mediumsized ports communities with focus on digital transformation to overcome to overcome challenges and increase their competitiveness. For agriculture, [10] a blockchain-bases system to improve the tracking issues related to asymmetric information in the post COVID-19 pandemic.

For tourism [13] proposed a solution to check and record a trail of individuals' immigration data about the coronavirus. In the donation area, [41] envisages the feasibility and reliability of developing a charity donation service system using blockchain technology in response to the complex service demands encountered by charity operators due to the COVID-19 epidemic and [42] demonstrated the blockchain impact on developing of charity 4.0, ensuring trust in philanthropy by avoiding potential cases of fraud and misappropriation of charitable funds as well as economic, financial and social repercussions.

For environment, was proposed an innovative approach for scaling-up and transformational change to secure a more effective, ethical and resilient future for marine protected and conserved areas in a post-COVID world [43] and analyzed the potential of blockchain technology as a game changer in solving some of the most pressing issues hindering the global recovery post COVID-19 to transition towards greener and more inclusive economy [44]. A blockchain network was designed for the food industry improves transparency throughout the supply chain to import cold chain products and certify the quality of the final product, eliminating malpractices that risk consumer safety and health [45].

Factors were identified for improvement in requirement engineering practices and blockchain platforms can make these factors more reliable and effective, helping to create successful projects that will reduce the rate of failure of projects of COVID-19 [34]. For education, a novel distance-learning solution that takes advantage of blockchain technology in 
Table 2 Application overview by paper title

\begin{tabular}{|c|c|c|c|c|}
\hline Title & Type & Platform & Use Case & Classification \\
\hline $\begin{array}{l}\text { Improvement of public distribution } \\
\text { system efficiency applying blockchain } \\
\text { technology during pandemic outbreak } \\
\text { (COVID-19) [1] }\end{array}$ & Hybrid & Hyperledger & Food supply chain and Data aggregation & CS \\
\hline $\begin{array}{l}\text { The role of blockchain to fight against } \\
\text { covid-19 [3] }\end{array}$ & NA & NA & $\begin{array}{l}\text { Contact tracing, User privacy protection } \\
\text { and Outbreak tracking }\end{array}$ & TC \\
\hline $\begin{array}{l}\text { Part 2: blockchain technology in health } \\
\text { care [6] }\end{array}$ & NA & NA & Traceability, trust and transparency & $\mathrm{TC}$ \\
\hline $\begin{array}{l}\text { Blockchain technology in current } \\
\text { agricultural systems: from techniques } \\
\text { to applications [10] }\end{array}$ & Private & NA & Food supply chain and Data aggregation & TC \\
\hline $\begin{array}{l}\text { Promoting trustless computation through } \\
\text { blockchain technology [13] }\end{array}$ & Private & Hyperledger & $\begin{array}{l}\text { Contact tracing, User privacy protection } \\
\text { and Data aggregation }\end{array}$ & TC \\
\hline $\begin{array}{l}\text { A comprehensive review of the covid- } 19 \\
\text { pandemic and the role of iot, drones, } \\
\text { ai, blockchain and } 5 \mathrm{~g} \text { in managing its } \\
\text { impact [14] }\end{array}$ & NA & NA & Data aggregation and Outbreak tracking & $\mathrm{TC}$ \\
\hline $\begin{array}{l}\text { Blockchain for covid-19: review, } \\
\text { opportunities and a trusted tracking } \\
\text { system [15] }\end{array}$ & Public & Ethereum & $\begin{array}{l}\text { Data aggregation, outbreak tracking and } \\
\text { Contact tracing }\end{array}$ & $\mathrm{CS}$ \\
\hline $\begin{array}{l}\text { Blockchain in healthcare: insights on } \\
\text { covid-19 [31] }\end{array}$ & Public & NA & $\begin{array}{l}\text { Data aggregation, Outbreak tracking and } \\
\text { Contact tracing }\end{array}$ & $\mathrm{TC}$ \\
\hline $\begin{array}{l}\text { At the epicenter of covid-19: the tragic } \\
\text { failure of the global supply chain for } \\
\text { medical supplies [32] }\end{array}$ & NA & NA & Medical supply chain & $\mathrm{TC}$ \\
\hline $\begin{array}{l}\text { An intelligent framework using } \\
\text { disruptive technologies for covid-19 } \\
\text { analysis [33] }\end{array}$ & NA & NA & Outbreak tracking & EC \\
\hline $\begin{array}{l}\text { Reliable requirements engineering } \\
\text { practices for covid-19 using blockchain } \\
\text { [34] }\end{array}$ & NA & NA & $\begin{array}{l}\text { Improve reliability and effectiveness of } \\
\text { projects }\end{array}$ & SU \\
\hline $\begin{array}{l}\text { Blockchain technology for winning } \\
\text { consumer loyalty social norm analysis } \\
\text { using structural equation modeling } \\
{[35]}\end{array}$ & NA & NA & Gain and maintain consumers loyalty & SU \\
\hline $\begin{array}{l}\text { Blockchain-based forward supply chain } \\
\text { and waste management for covid-19 } \\
\text { medical equipment and supplies [36] }\end{array}$ & Public or Private & Ethereum & Medical supply chain & $\mathrm{TC}$ \\
\hline $\begin{array}{l}\text { Blockchain-based solution for distribution } \\
\text { and delivery of covid-19 vaccines [37] }\end{array}$ & Hybrid & Ethereum & Medical supply chain & TC \\
\hline $\begin{array}{l}\text { Privacy-preserving contact tracing in } \\
\text { 5G-integrated and blockchain-based } \\
\text { medical applications [38] }\end{array}$ & Hybrid & Hyperledger & $\begin{array}{l}\text { Contact tracing and User privacy } \\
\text { protection }\end{array}$ & $\mathrm{TC}$ \\
\hline $\begin{array}{l}\text { VPassport: a digital architecture to support } \\
\text { social restart during the SARSCOV-2 } \\
\text { pandemic [39] }\end{array}$ & Private & NA & $\begin{array}{l}\text { Contact tracing and Clinical trial } \\
\text { management }\end{array}$ & TC \\
\hline $\begin{array}{l}\text { Cross-border capacity-building for port } \\
\text { ecosystems in small and medium-sized } \\
\text { baltic ports [40] }\end{array}$ & NA & NA & Training and Competitiveness & $\mathrm{EC}$ \\
\hline $\begin{array}{l}\text { Developing a reliable service system of } \\
\text { charity donation during the covid-19 } \\
\text { outbreak [41] }\end{array}$ & Hybrid & Ethereum & Donation tracking & \\
\hline $\begin{array}{l}\text { Managing charity } 4.0 \text { with blockchain: a } \\
\text { case study at the time of covid-19 [42] }\end{array}$ & Public & VeChain and Ethereum & Donation tracking & EC \\
\hline $\begin{array}{l}\text { Marine protected and conserved areas in } \\
\text { the time of covid [43] }\end{array}$ & NA & NA & Protect and Conserve areas & $\mathrm{TC}$ \\
\hline
\end{tabular}


Table 2 (continued)

\begin{tabular}{|c|c|c|c|c|}
\hline Title & Type & Platform & Use Case & Classification \\
\hline $\begin{array}{l}\text { Blockchain-based solutions in achieving } \\
\text { SGDs after covid19 [44] }\end{array}$ & NA & NA & $\begin{array}{l}\text { Food security and Support to sustainable } \\
\text { development }\end{array}$ & $\mathrm{TC}$ \\
\hline $\begin{array}{l}\text { Blockchain-based traceability system } \\
\text { that ensures food safety measures to } \\
\text { protect consumer safety and covid-19 } \\
\text { free supply chains [45] }\end{array}$ & Hybrid & Hyperledger & Data aggregation and Food security & $\mathrm{EC}$ \\
\hline $\begin{array}{l}\text { NOTA: a novel online teaching and } \\
\text { assessment scheme using blockchain } \\
\text { for emergency cases [46] }\end{array}$ & Private & Ethereum & $\begin{array}{l}\text { Easy learning, Easy teaching, Data } \\
\text { aggregation }\end{array}$ & $\mathrm{EC}$ \\
\hline $\begin{array}{l}\text { Disruptive technologies for labor market } \\
\text { information system implementation } \\
\text { enhancement in the UAE a conceptual } \\
\text { perspective [47] }\end{array}$ & NA & NA & Data-driven and Service-oriented & $\mathrm{EC}$ \\
\hline $\begin{array}{l}\text { Blockchain-based healthcare workflow } \\
\text { for telemedical laboratory in federated } \\
\text { hospital iot clouds [48] }\end{array}$ & Public and Hybrid & Ethereum & $\begin{array}{l}\text { Clinical trial management, Data } \\
\text { aggregation, User privacy protection } \\
\text { and Contact tracing }\end{array}$ & $\mathrm{CS}$ \\
\hline $\begin{array}{l}\text { CovidChain: an anonymity preserving } \\
\text { blockchain based framework for } \\
\text { protection against covid-19 [49] }\end{array}$ & Hybrid & NA & $\begin{array}{l}\text { Contact tracing, User privacy and Outbreak } \\
\text { tracking }\end{array}$ & $\mathrm{TC}$ \\
\hline $\begin{array}{l}\text { Construction of a medical resource sharing } \\
\text { mechanism based on blockchain } \\
\text { technology: evidence from the medical } \\
\text { resource imbalance of China [50] }\end{array}$ & NA & NA & Medical supply chain, User privacy & $\mathrm{EC}$ \\
\hline $\begin{array}{l}\text { How blockchain helps to enhance healthcare } \\
\text { quality potential impact on crisis situations } \\
\text { like covid-19 pandemic [51] }\end{array}$ & NA & NA & $\begin{array}{l}\text { Clinical trial management, Medical } \\
\text { education, Contact Tracing and Data } \\
\text { aggregation }\end{array}$ & $\mathrm{TC}$ \\
\hline $\begin{array}{l}\text { Proposed framework for dealing covid-19 } \\
\text { pandemic using blockchain technology } \\
\text { [52] }\end{array}$ & Private & R3 Corda & Medical supply chain & $\mathrm{TC}$ \\
\hline $\begin{array}{l}\text { Is blockchain for internet of medical } \\
\text { things a panacea for covid-19 pandemic? } \\
\text { [53] }\end{array}$ & Private & NA & $\begin{array}{l}\text { Contact tracing, and medical supply } \\
\text { chain }\end{array}$ & $\mathrm{TC}$ \\
\hline
\end{tabular}

order to proposes teaching quality, course deployment and student's examination [46]. A framework was developed to improve the future of the labor market within COVID-19 through an integrated information exchange system [47].

Fig. 7 Main application areas

11

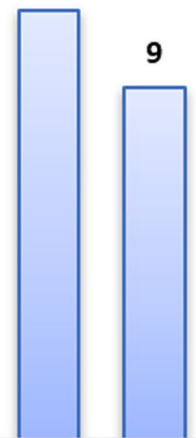

3
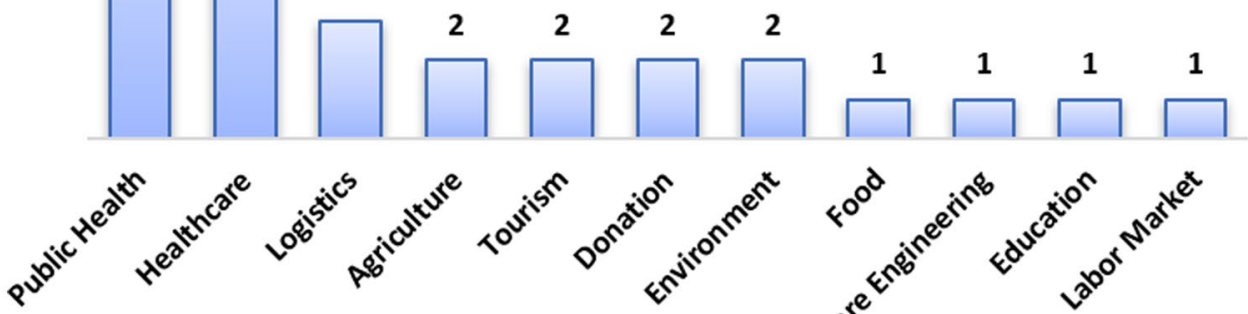

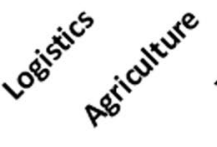

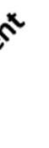

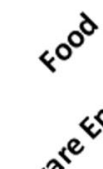




\subsection{Application overview}

As a way to facilitate an overview of the blockchain technology application of the studied papers, a table containing information on each one was built (see Table 2), adapting the use cases definition from [15].

As can be seen, the most adopted type of blockchain is hybrid. Examples are [41] that show that for a charitable donation service it is more appropriate to adopt a hybrid form involving public and alliance blockchain, combining decentralization and data authenticity, due to the complex conditions of relationship between various organizations and individuals. Likewise, [1] also state that a hybrid blockchain is more suitable for targeted public distribution systems.

Regarding the platform, Ethereum was the most used. It is the most active blockchain platform in the world for blockchain practitioners and researchers, because of its application platform and development of the blocking chain work well, be well recognized, mature and stable in technology [54].

\section{Findings and discussion}

This research reveals during the outbreak there was an intense increase in the dissemination of disinformation, supply chain disruptions and the amount of medical data, and the existing platforms do not have the ability to validate the authenticity of data and ensure effective sharing between the parties involved.

In Table 3 it is possible to see the relation between paper, area and application. The denominations are: for "areas":

A1 - Public Health;

A2 - Healthcare;

A3 - Logistics;

A4 - Agriculture;
Table 3 Review overview

\begin{tabular}{|c|c|c|c|c|c|c|c|c|c|c|c|c|c|c|c|c|}
\hline Authors & A1 & A2 & A3 & A4 & A5 & A6 & A7 & A8 & A9 & A10 & A11 & AP1 & AP2 & AP3 & AP4 & AP5 \\
\hline [1] & & & $X$ & & & & & & & & & $X$ & & $X$ & & \\
\hline [3] & $X$ & $X$ & & & & & & & & & & $X$ & & & $X$ & \\
\hline [6] & & $X$ & & & & & & & & & & $X$ & & $X$ & $X$ & $X$ \\
\hline [10] & & & & $X$ & & & & & & & & $X$ & $X$ & & & \\
\hline [13] & & & & & $X$ & & & & & & & $X$ & & $X$ & & \\
\hline [14] & $X$ & & & & & & & & & & & $X$ & $X$ & & & $X$ \\
\hline [15] & $X$ & & & & & & & & & & & $X$ & $X$ & & & \\
\hline [31] & & $X$ & & & & & & & & & & & $X$ & $X$ & $X$ & $X$ \\
\hline [32] & $X$ & & & & & & & & & & & $X$ & & $X$ & & $X$ \\
\hline [33] & $X$ & $X$ & & & & & & & & & & & $X$ & $X$ & & \\
\hline [34] & & & & & & & & & $X$ & & & & & & & $X$ \\
\hline [35] & & & & & $X$ & & & & & & & $\mathrm{X}$ & & $X$ & & \\
\hline [36] & & $X$ & & & & & & & & & & $X$ & $X$ & $X$ & & \\
\hline [37] & $X$ & & & & & & & & & & & $X$ & & & & $X$ \\
\hline [38] & $X$ & $X$ & & & & & & & & & & $X$ & & & $X$ & \\
\hline [39] & $X$ & & & & & & & & & & & $\mathrm{X}$ & & & & $X$ \\
\hline [40] & & & $X$ & & & & & & & & & & & $X$ & & $X$ \\
\hline [41] & & & & & & $X$ & & & & & & $X$ & $X$ & $X$ & & \\
\hline [42] & & & & & & $X$ & & & & & & $X$ & $X$ & $X$ & & \\
\hline [43] & & & & & & & $X$ & & & & & & & $X$ & & $X$ \\
\hline [44] & & & & & & & $X$ & & & & & $X$ & $X$ & $X$ & & \\
\hline [45] & & & & & & & & $X$ & & & & $X$ & $X$ & $X$ & & \\
\hline [46] & & & & & & & & & & $X$ & & $X$ & & & $X$ & $X$ \\
\hline [47] & & & & & & & & & & & $X$ & $X$ & $X$ & & & $X$ \\
\hline [48] & & $X$ & & & & & & & & & & $X$ & & & $X$ & $X$ \\
\hline [49] & $X$ & & & & & & & & & & & $\mathrm{X}$ & & & $X$ & \\
\hline [50] & $X$ & & & & & & & & & & & $X$ & & $X$ & $X$ & \\
\hline [51] & & $X$ & & & & & & & & & & $X$ & & $X$ & $X$ & $X$ \\
\hline [52] & $X$ & & & & & & & & & & & X & $X$ & & $X$ & \\
\hline [53] & & $X$ & & & & & & & & & & $X$ & & $X$ & $X$ & \\
\hline
\end{tabular}


A5 - Tourism;

A6 - Donation;

A7 - Environment;

A 8 - Food;

A9 - Software Engineering;

A10 - Education;

A11 - Labor Market.

And for "application":

AP1 - Traceability;

AP2 - Transparency;

AP3 - Trust;

AP4 - Privacy;

AP5 - Automation.

\subsection{Challenges and opportunities}

Analyzing the results, it is possible to observe that the blockchain presents sufficient opportunities to become an integral part of the fight against COVID-19. However, it also presents challenges that need to be addressed.

About the challenges of the papers observed, it is possible to group them into:

Scalability: as blockchain throughput is lower than conventional centralized databases, this technology often suffers from lack of scalability;

$\bigcirc$ Integration with legal issues and data privacy: the transparency and distributed data storage can highly affect data privacy. The methods of data processing, storage and visualization must comply with the privacy laws (f.e. GDPR in USA and LGPD in Brazil);

$\bigcirc$ Security risks: the information is transparent to all nodes in the network and in some cases the decentralization makes the system highly fault-tolerant, and this is a problem since the technology may be susceptible to hacker attacks;

$\bigcirc$ Smart contracts development: A poorly designed or poorly written smart contract can exhibit low performance, limited security, and high execution transaction rates.

$\bigcirc$ Resource utilization: system operating costs remain high and it is necessary to have a high level of data storage capacity. In addition, some platforms require "fuel" payments to run the functions, which in some cases, may be difficult to estimate the cost of execution;

$\bigcirc$ Personnel problems: there is still resistance to change due to the lack of information about blockchain and its potential and there is also a lack of qualified professionals;
Applicability: studies need to initiate tests in real cases to effectively validate the application.

Blockchain technology in the context of COVID-19 has several cases of potential use, such as:

Traceability of collected data, in order to control pandemics (medical data, data about virus spread and patient movement) or to control failures and disruptions in distribution (food and medical supply distribution);

$\bigcirc$ Transparency in sharing the information collected, whether it is between hospitals and patients to facilitate medical care, governments and citizens to control virus transmission, or in the medical or food supply chain;

$\bigcirc$ Trust in data, in demand variation, in information sources and in stakeholders. Immutability and synchronization by consensus protocols are great attractions for dealing not only with pandemics and disruptions, but also with business;

$\bigcirc$ Privacy in information sharing (patients, government, enterprises, hospitals, etc.). In the current context, the privacy of information has become an extremely sensitive issue. Although privacy is still a major challenge, the possibility of developing smart contracts and permissioned networks to control access to the data in the chain ensures confidentiality and data privacy through blockchain;

$\bigcirc$ Automation: Real-time data availability with easy updating and access to participants. The development of smart contracts helps in the automation of decision making and, in the updating and availability of data for the participants in the chain. In situations such as medical, government or supply chain data, this can be a great alternative.;

$\bigcirc$ Data control: in epidemic disasters, or even nowadays, the availability of large amounts of data is increasingly in evidence. Integrating blockchain with big data for disaster control and sharing or business rules can be an attractive

The categorization of the improvements assists in identifying the research focus for academics and professionals. The purpose of this section was not to report limitations as failures, but rather to highlight possible research opportunities and applications for future work.

It is evident that the adoption of enabling technologies, such as blockchain, can support proper implementation of many use cases, such as in the effective planning of operation, the distribution of resources and in counteracting misinformation during pandemics.

The impacts caused by the unprecedented transmission of COVID-19 have given rise to new challenges that are 
shaking the structures of humanity. In this context, there has been a significant increase in demand for science, technology and medicine. There is a balance between technology and medicine related to this subject, because although blockchain is a very technological topic, the fact that it is related to COVID-19 makes evident that its main application is in the health field, which is the most affected by the pandemic.

The main applications of blockchain to support the population in dealing with COVID-19 are associated with control and management of infected areas and movement of individuals, remote care and information sharing between hospitals and patients, better distribution of medical equipment, vaccines, and food, control of information shared between individuals, and security in donation systems.

Opportunities still existing for exploration within this area. Many studies use only blockchain as a disruptive technology, but there are possibilities for other technologies to be explored to mitigate the effects of the pandemic, even being integrated with blockchain to optimize results, such as big data and multi-robot and artificial intelligence.

The use of hybrid blockchain and the Ethereum platform is a trend in the papers analyzed, but still presents security and protection flaws, opening opportunities for blockchain development on other platforms such as Hyperledger and R3 Corda. Moreover, with data sharing and information security issues becoming increasingly important in today's discussions, it is essential that smart contracts be adapted to ensure that laws will be followed, while at the same time meeting all the requirements of the network participants.

The topic is still relatively new, as we are still living the pandemic. The knowledge needed to identify the range of new technologies and the impact they will have on people's lives is still growing. Since some effects caused by this pandemic will not be carried along with its end, there are still opportunities for future researchers to conduct new researchers with novel solutions involving blockchain, especially in empirical studies, which is still a gap to be addressed.

\section{Conclusion}

This study aimed to answer how blockchain has helped the world overcome the various difficulties imposed by the pandemic of COVID-19. All the analyses conducted throughout this study provide insights into how blockchain is being used for this purpose. Several sectors are being contemplated with proposals of blockchain systems, mainly the health one, considering the impact of the crisis on people's lives. For the scope of COVID-19, the most used blockchain case is related to data collection and distribution, involving several stakeholders, such as hospitals, patients, companies and the government. The limitations of this article are related to the time of research. As the pandemic is still in course at the moment of this paper's publication, it is recommended to update the data in future research to understand the progress of the proposals. This paper contributes to the understanding of academics and professionals about the potential use of blockchain in pandemic situations, more specifically COVID-19 and opens opportunities for applications in other areas and development of new models.

Authors' contributions Optional-please review the submission guidelines from the journal whether statements are mandatory.

Funding Not applicable.

Availability of data and material Not applicable.

Code availability Not applicable.

\section{Declarations}

Conflicts of interest The authors declare that they have no conflict of interest.

\section{References}

1. Kumar A. Improvement of public distribution system efficiency applying blockchain technology during pandemic outbreak (COVID-19). J Humanit Logist Supply Chain Manag. 2020; 120431. https://doi.org/10.1108/JHLSCM-06-2020-0050.

2. Abdel-basset M, Chang V, Nabeeh NA. An intelligent framework using disruptive technologies for COVID-19 analysis. Technol Forecast Soc Chang. 2020. https://doi.org/10.1016/j.techfore. 2020.120431.

3. Kalla A, Hewa T, Mishra AR. The role of blockchain to fight against COVID-19. IEEE Eng Manag Rev. 2020;48(3):85-96. https://doi.org/10.1109/EMR.2020.3014052.

4. Alsamhi SH, Lee B, Guizani M, Kumar N, Qiao Y, Liu X. Blockchain for decentralized multi-drone to combat COVID-19 and future pandemics : framework and proposed solutions. Trans Emerg Telecommun Technol. 2021;e4255. https://doi.org/10. 1002/ett.4255.

5. Alsamhi SH, Lee B. Blockchain-empowered multi-robot collaboration to fight COVID-19 and future pandemics. IEEE Access. 2021;9:44173-97. https://doi.org/10.1109/ACCESS. 2020.3032450 .

6. Tan L, Tivey D, Maddern G, Kopunic H, Babidge W, Langley S. Part 2: Blockchain technology in health care. ANZ J Surg. 2020;90:2415-9. https://doi.org/10.1111/ans.16455.

7. Kritikos M. Ten technologies to fight coronavirus. Eur Parliam Res Serv. 2020. https://www.europarl.europa.eu/RegData/etudes/ IDAN/2020/641543/EPRS_IDA(2020)641543_EN.pdf. Accessed 27 Dec 2020.

8. Sylim P, Liu F, Marcelo A, Fontelo P. Blockchain technology for detecting falsified and substandard drugs in distribution : pharmaceutical supply chain intervention. JMIR Res Protoc. 2018;7:1-12. https://doi.org/10.2196/10163.

9. Dwivedi SK, Amin R, Vollala S. Blockchain based secured information sharing protocol in supply chain management system with key distribution mechanism. J Inf Secur Appl. 2020;54. https:// doi.org/10.1016/j.jisa.2020.102554. 
10. Lin W, Huang X, Fang HUI, Wang V, Hua Y, Wang J, et al. Blockchain technology in current agricultural systems : from techniques to applications. IEEE Access. 2020;8. https://doi.org/10.1109/ ACCESS.2020.3014522.

11. Saha A, Amin R, Kunal S, Vollala S, Dwivedi SK. Review on "blockchain technology based medical healthcare system with privacy issues." Secur Priv. 2019;2(5):1-14. https://doi.org/10. $1002 /$ spy 2.83.

12. Alhadhrami Z, Alghfeli S, Alghfeli M, Abedlla JA, Shuaib K. Introducing blockchains for healthcare. Int Conf Electr Comput Technol Appl ICECTA. 2017;1-4. https://doi.org/10.1109/ ICECTA.2017.8252043.

13. Pandey P, Litoriya R. Promoting trustless computation through blockchain technology. Natl Acad Sci Lett. 2020. https://doi.org/ 10.1007/s40009-020-00978-0.

14. Chamola V, Hassija V, Gupta V, Guizani M. A comprehensive review of the COVID-19 pandemic and the role of iot, drones, ai , blockchain , and 5G in managing its impact. Spec Sect Deep Learn algorithms internet Med things. 2020;(April):90225-65. https://doi.org/10.1109/ACCESS.2020.2992341.

15. Marbouh D, Abbasi T, Maasmi F, Omar IA, Debe MS, Salah K, et al. Blockchain for COVID-19: review, opportunities, and a trusted tracking system. Arab J Sci Eng [Internet]. 2020;45(12):9895-911. https://doi.org/10.1007/s13369-020-04950-4.

16. Gil AC. Como elaborar projeto de pesquisa. Vol. 38, Revista Brasileira de Educação Médica. 2002. 519-531 p.

17. Gil AC. Métodos e técnicas de pesquisa. Vol. 10, Editora Atlas. 2008. 83-85 p.

18. Colicchia C, Strozzi F. Supply chain risk management: A new methodology for a systematic literature review. Supply Chain Manag. 2012;17(4):403-18. https://doi.org/10.1108/ 13598541211246558.

19. Kitchenham B. Procedures for performing systematic reviews. Keele Univ Tech Rep TR/SE-0401. 2004;1-27.

20. Webster J, Watson RT. Analyzing the past to prepare for the future: writing a literature review. MIS Q. 2002;26(2):xiii-xxiii.

21. Moher D, Liberati A, Tetzlaff J, Altman DG. Preferred reporting items for systematic reviews and meta-analyses: the PRISMA statement. J Clin Epidemiol. 2009;62(10):1006-12. https://doi. org/10.1016/j.jclinepi.2009.06.005.

22. Budakoğlu1 Iİ, Sayılır MÜ, Kıyak YS, Coşkun1 Ö, Kula S. Telemedicine curriculum in undergraduate medical education: a systematic search and review. Health Technol (Berl). 2021;11:77381. https://doi.org/10.1007/s12553-021-00559-1.

23. Aria M, Cuccurullo C. Bliometrix: an r-tool for comprehensive science mapping analysis. J Informetr. 2017;11(4):959-75. https:// doi.org/10.1016/j.joi.2017.08.007.

24. Johns Hopkins University and Medicine. New covid-19 cases worldwide. 2021. https://coronavirus.jhu.edu/data/new-cases. Accessed 22 July 2021.

25. World Health Organization. WHO coronavirus (covid19) dashboard. 2021. https://covid19. who.int/?gclid= CjwKCAjwzIH7BRAbEiwAoDxxTqPnrocpIjc5MtniSEVU\%20h-\% 20CUzVXqrklwl24KKsi4KICxnzNUDO7g8BoCGo8QAvD\% 20BwE. Accessed 22 July 2021.

26. Burki T. China's successful control of COVID-19. Lancet Infect Dis. 2020;20(11):1240-1. https://doi.org/10.1016/S14733099(20)30800-8.

27. Deutsche Welle. Austrália zera transmissões locais de COVID-19. 2020. https://www.dw.com/pt-br/austr\%C3\%A1lia-zera-transmiss\% C3\%B5es-locaisde-COVID-19/a-55465334. Accessed 27 Dec 2020.

28. World Health Organization. List of vaccine producing countries with functional NRAs. 2021. https://www.who.int/initiatives/wholisted-authority-reg-authorities/list-of-vaccine-prod-countries. Accessed 22 July 2021.
29. Gibney E. Whose coronavirus strategy worked best? scientists hunt most effective policies. Nature. 2020;581(7806):15-7.

30. Costa LBM, Godinho FM. Lean healthcare: review, classification and analysis of literature. Prod Plan Control. 2016;27(10):823-36. https://doi.org/10.1080/09537287.2016.1143131.

31. Fusco A, Dicuonzo G, Atti VD, Tatullo M. Blockchain in healthcare : insights on COVID-19. Int J Environ Res Public Health. 2020. https://doi.org/10.3390/ijerph17197167.

32. Bhaskar S, Tan J, Bogers MLAM, Minssen T, Badaruddin H, Israeli-Korn S, et al. At the epicenter of COVID-19-the tragic failure of the global supply chain for medical supplies. Front Public Heal. 2020;8:1-9. https://doi.org/10.3389/fpubh.2020.562882.

33. Abdel-Basset M, Chang V, Nabeeh NA. An intelligent framework using disruptive technologies for COVID-19 analysis. Technol Forecast Soc Change. 2021;163: 120431. https://doi.org/10. 1016/j.techfore.2020.12043.

34. Shahzad B, Javed I, Shaikh A, Sulaiman A, Abro A, Ali MM. Reliable requirements engineering practices for COVID-19 using blockchain. Sustainability. 2021;13(12):6748. https://doi.org/10. 3390/su13126748.

35. Pérez-Sánchez M de los Á, Tian Z, Barrientos-Báez A, GómezGalán J, Li H. Blockchain technology for winning consumer loyalty: Social norm analysis using structural equation modeling. Mathematics. 2021;9(5):1-18. https://doi.org/10.3390/ math9050532.

36. Ahmad RW, Salah K, Jayaraman R, Yaqoob I, Omar M, Ellahham $\mathrm{S}$. Blockchain-based forward supply chain and waste management for COVID-19 medical equipment and supplies. IEEE Access. 2021;9:44905-27. https://doi.org/10.1109/ACCESS.2021.3066503.

37. Musamih A, Jayaraman R, Salah K, Hasan HR, Yaqoob I, AlHammadi Y. Blockchain-based solution for distribution and delivery of COVID-19 vaccines. IEEE Access. 2021;9:71372-87. https://doi.org/10.1109/ACCESS.2021.3079197.

38. Zhang C, Xu C, Sharif K, Zhu L. Privacy-preserving contact tracing in 5G-integrated and blockchain-based medical applications. Comput Stand Interfaces. 2021;77: 103520. https://doi.org/10. 1016/j.csi.2021.103520.

39. Capece G, Bazzica P. Vpassport: A digital architecture to support social restart during the SARS-CoV-2 pandemic. Sustain. 2021;13(7). https://doi.org/10.3390/su13073945

40. Meyer C, Gerlitz L, Henesey L. Cross-border capacity-building for port ecosystems in small and medium-sized baltic ports. TalTech J Eur Stud. 2021;11(1):113-32. https://doi.org/10.2478/ bjes-2021-0008.

41. Wu H, Zhu X. Developing a reliable service system of charity donation during the COVID-19 outbreak. IEEE Access. 2020;8:154848-60. https://doi.org/10.1109/ACCESS.2020. 3017654.

42. Rangone A, Busolli L. Managing charity 4.0 with blockchain: a case study at the time of COVID-19. Int Rev Public Nonprofit Mark. 2021. https://doi.org/10.1007/s12208-021-00281-8.

43. Phua C, Andradi-Brown DA, Mangubhai S, Ahmadia GN, Mahajan SL, Larsen K, et al. Marine protected and conserved areas in the time of covid. Parks. 2021;27:85-102. https://doi.org/ 10.2305/IUCN.CH.2021.PARKS-27-SICP.en.

44. Aysan AF, Bergigui F, Disli M. Blockchain-based solutions in achieving SDGs after COVID-19. J Open Innov Technol Mark Complex. 2021;7(2):151. https://doi.org/10.3390/joitmc7020151.

45. Iftekhar A, Cui X. Blockchain-based traceability system that ensures food safety measures to protect consumer safety and COVID-19 free supply chains. Foods. 2021;10(6):1289. https:// doi.org/10.3390/foods10061289.

46. Cheriguene A, Kabache T, Kerrache CA, Calafate CT, Cano JC. NOTA : a novel online teaching and assessment scheme using 
blockchain for emergency cases. Educ Inf Technol. 2021. https:// doi.org/10.1007/s10639-021-10629-6.

47. Goher G, Masrom M, Amrin A, Rahim NA. Disruptive technologies for labor market information system implementation enhancement in the UAE: A Conceptual Perspective. Int J Adv Comput Sci Appl. 2021;12(2):370-9. https://doi.org/10.14569/IJACSA. 2021.0120247.

48. Celesti A, Ruggeri A, Fazio M, Galletta A, Villari M, Romano A. blockchain-based healthcare workflow for tele-medical laboratory in federated hospital iot clouds. Sensors. 2020;20(9):2590. https:// doi.org/10.3390/s20092590.

49. Choudhury H, Goswami B, Gurung SK. CovidChain: An anonymity preserving blockchain based framework for protection against COVID-19. Inf Secur J. 2021;00(00):1-24. Available from: https://doi.org/10.1080/19393555.2021.1921315.

50. Liu H, Liu Y. Construction of a medical resource sharing mechanism based on blockchain technology: Evidence from the medical resource imbalance of china. Healthc. 2021;9(1). https://doi.org/ 10.3390/healthcare9010052.
51. Alanazi AMM. How blockchain helps to enhance healthcare quality: potential impact on crisis situations like COVID-19 pandemic. Int J Qual Res. 2020;14(4):1059-80. https://doi.org/10.24874/ IJQR14.04-05.

52. Gupta M, Kumar V, Yadav V, Singh RK, Sadim M. Proposed framework for dealing COVID-19 pandemic using blockchain technology. J Sci Ind Res (India). 2021;80(3):270-5.

53. Li X, Tao B, Dai HN, Imran M, Wan D, Li D. Is blockchain for internet of medical things a panacea for COVID-19 pandemic? Pervasive Mob Comput [Internet]. 2021;75:101434. Available from: https://doi.org/10.1016/j.pmcj.2021.101434.

54. Wood G. Ethereum: a secure decentralised generalised transaction ledger. Ethereum Proj Yellow Pap. 2014;1-32.

Publisher's Note Springer Nature remains neutral with regard to jurisdictional claims in published maps and institutional affiliations. 